Original Article

\title{
LONG TERM CONDITIONS AND MENTAL HEALTH: AN AUDIT OF LOCAL DATA
}

\author{
HANA MORRISSEY ${ }^{1}$, OLUTAYO ARIKAWE ${ }^{1,2}$, PAMELA PAUL ${ }^{2,3}$, MANJINDER SANDHU², ZAIN SADIQUE ${ }^{3}$, PATRICK \\ BALL ${ }^{1}$
}

1School of Pharmacy, Faculty of Science and Engineering, University of Wolverhampton, United Kingdom, ${ }^{2}$ The Priory Community

Pharmacy, Dudley, United Kingdom, ${ }^{3}$ Primary Care Network, Dudley Clinical Commissioning Group, United Kingdom

Email: hana.morrissey@wlv.ac.uk

Received: 08 Nov 2020, Revised and Accepted: 10 Jan 2021

\begin{abstract}
Objective: Studies have shown that mental health is affected by poor physical health, with people living in the deprived area are the most affected. Community Pharmacists potentially have a new role in supporting people with mental illness and dementia to manage their medications. The aim of this local audit was to compare the local population to the national and global population, to inform the development and provision of local pharmacy mental health screening services, to support patients diagnosed with long-term conditions.
\end{abstract}

Methods: This project was designed as an audit of anonymised local data, to inform the development of services offered by community pharmacies to improve adherence to therapy amongst patients diagnosed with long-term conditions in the Black Country, UK. It forms part of a larger study granted ethical approval by the Health Research Authority in 2018. It was carried out against the background of the Covid-19 epidemic. A total of 652 patients pharmacy records were reviewed between March and April 2020. No patient identifiers were included in the reviewed data.

Results: This means that the results of this analysis might not be applicable to the entire local population outside the 31-90 y of age range.

Conclusion: It is was demonstrated during COVID-19 that pharmacists are well-positioned as easily accessible health care facilities to support patients, especially when the other NHS facilities are stretched or closed. Community pharmacies are in a position to offer large-scale screening programs such as self-completed anxiety, depression and cognitive function screening surveys and refer to general practitioners for further investigations. It is also recommended that the New Medicines Service include mental health disorder patients prescribed pharmacological therapy and to allow the pharmacists appropriate access to medical records to facilitate safe, integrated and effective patient care.

Keywords: Long term conditions, Mental illness, Community pharmacists, Mental health and memory screening

(C) 2021 The Authors. Published by Innovare Academic Sciences Pvt Ltd. This is an open access article under the CC BY license (https://creativecommons.org/licenses/by/4.0/)

DOI: https://dx.doi.org/10.22159/ijcpr.2021v13i2.51552. Journal homepage: https://innovareacademics.in/journals/index.php/ijcpr

\section{INTRODUCTION}

The effect of mental ill-health (MIH) on an individual's quality of life and ability to self-care their other long-term conditions cannot be ignored [1]. Medications to manage MIH are dispensed by community pharmacies with many patients taking antipsychotic and anti-depressant drugs [1]. The community pharmacy workforce have the most contact with patients, as they are easily accessible and well-placed within the community [2]. According to the Royal Pharmaceutical Society (RPS), one in six adults in the United Kingdom (UK) experience at least one diagnosable MIH problem at any given time, with a life-time incidence of 1 in 4 [1]. MIH has been identified by the Department of Health (DoH) as the third-ranked illness category affecting the nation's health [2]. Studies have shown that MIH is affected by poor physical health, with people living in deprived areas most affected [3]. People who have MIH have been shown to be at great risk of cardiovascular diseases (CVD) and vice versa; where people diagnosed with CVDs and diabetes have increased risk of depression, anxiety and some types of dementia [3]. People with long-term conditions attend community pharmacies regularly for ongoing supplies and can be supported by the pharmacy workforce. MIH is multifaceted and influenced by a wide range of economic, social, physical, environmental and individual factors. According to The World Health Organisation (WHO), 'People with mental disorders experience disproportionately higher rates of disability and mortality' [4]. Globally, the disparity between the need for treatment and receiving that treatment is large as health systems have not yet caught up with the increase in people reaching out for mental health support [4]. Currently, community pharmacies are not part of the MIH support effort and many community pharmacists and their staff are lacking MIH awareness and training [4]. The vision of the WHO action plan of 2012-2020 was a world in which mental health is valued, promoted and protected. Their goal is nations working to create a world where MIH is prevented and those affected receive treatment rendering them able to enjoy their human rights through access to timely, high quality, culturally-appropriate health and social care to promote recovery within a society free from stigmatization and discrimination $[4,5]$. According to the Mental Health Foundation, only $13 \%$ of the population reported living with high levels of good mental health [5]. Household income and economic activity play a major part in mental health state; three out of four people in the UK living in the lowest household income bracket (less than $£ 1,200$ per month) report having experienced a MIH compared to 6 in 10 of the highest household income bracket (over $€ 3,701 \mathrm{pm}$ ) [5]. The majority (85\%) of unemployed people experience MIH problems compared to $66 \%$ of employed people and just $50 \%$ of retirees. This rises to seven in 10 women, young adults (18-34 y old) and people living alone [5]. The mental health policy group manifesto highlighted that people with MIH problems may be susceptible to increased risk of developing chronic physical health problems. This is due to the effects of medication such as antipsychotics and antidepressants prescribed to treat MIH, with one in three of 100,000 'avoidable deaths' annually, is people with MIH [6]. In comparison to the general population, people with serious MIH experience a higher risk of diabetes (up to 2X), hypertension (up to $3 \mathrm{X}$ ), dying from coronary heart diseases (up to $3 \mathrm{X}$ ), deaths from respiratory diseases for people with schizophrenia (up to10X) and dying prematurely under the age of 50 (4X) [6].

Community pharmacists could also potentially have a role in supporting people with dementia and their carers to manage their medications and contribute to the early detection of dementia [7]. The impact that Pharmacists and their teams can have in supporting people with dementia has been nationally recognized; hence the requirement for the 'healthy living pharmacy' workforce to be 'Dementia Friends. 
Approximately one in three GP Appointments relate to $\mathrm{MIH}$; however, the provision of treatment can continue long after the diagnosis [5]. MIH receives $5.8 \%$ of the total UK health research budget but represents $23 \%$ of service demand [3]. There is a need to make healthcare more accessible to everyone and to reduce health inequalities among communities, especially within health postcodes and deprivation indexes [8]. The NHS 'Five Year Forward View' identified mental health as the cause of disability for one in every four people at some point of their life [9]. More than 16 million people in England are diagnosed with long-term physical health condition and according to the NHS, one out of three of those will experience $\mathrm{MIH}[10]$.

Pharmacists have a role to play in health promotion, to create awareness about MIH. Wheeler et al. concluded it would be a missed opportunity for policymakers not to consider using the skills of the community pharmacy workforce to support mental health services [11]. Another study estimated that around $50 \%$ of people living with long-term conditions do not adhere to taking their medication after a period of six months. They estimated this cost the USA around US $\$ 300$ billion annually [12]. It is important that prescribers spend time discussing adherence to their medication with their patients and factors that may influence this. However, with a stretched NHS and limited resources to enable prescribers to spend more time with patients, it is important that healthcare professionals support each other in optimising the patients' journey and experience [13]. The pharmacy workforce are well-placed to identify non-adherence early and to support or signpost the patient to the right professionals [12]. In the UK, only $24 \%$ of those with a common mental health problem and $65 \%$ of those with psychotic problems have received any treatment, in comparison $91 \%$ of people with hypertension and $94 \%$ of people with diabetes [14].

Medicine use review (MUR) is a service provided by community pharmacists. People with MIH are known to have difficulty with adherence to their medication regimen $[12,14]$. In addition to their knowledge about medications, undertaking mental health first aid (MHFA) training empowers the pharmacy workforce to recognize the early signs of MIH and to have the confidence to provide the appropriate initial help. One of the recommendations the mental health five-year forward view is for people with MIH to have quick access to evidence-based care for the biological, psychological and social issues related to their needs, in the least restrictive setting and as close to home as possible [15].

Medication used in treating long term conditions including MIH has different side effects, of which some are serious [16]. Pharmacists can identify these through the use of the new medicine service (NMS) available at their UK community pharmacies. The NMS was introduced in England in 2011, to support people who are starting a new medication for their long-term condition [17]. Four specific patient groups were found to be affected and experienced a reduction in the rate of hospital admissions. These are patients diagnosed with asthma or chronic obstructive pulmonary disease (COPD), hypertension (HTN), Type 2 diabetes mellitus (T2DM), or those who had a prescription of anticoagulant and antiplatelet agents [17]. The service is carried out at the community pharmacy where the patient collects their medication for the first time. Problems encountered when patients first start taking their medication can lead to the patient ceasing the medication $[17,18]$. Early side effects may lead to many patients to stop taking their medications as prescribed or for the full duration for which they are prescribed. The NMS provides an avenue for the pharmacist to support the patient through providing information and support on their medication and treatment and also provide an early referral to the prescriber if the medication proves unsuitable or if the side effect will require discontinuing the medication $[17,18]$. To participate in the NMS service, patients give their written consent by signing a prepopulated, approved form while presenting the prescription for the first time at their pharmacy. The patients then receive a consultation with the community pharmacist 7-14 d after starting their medication and then another follow-up consultation between 14-21 d after starting. This can be performed either face to face, or over the telephone. The pharmacy can identify adherence behaviour at this point and provide support to improve adherence, ensuring that the medication benefit is optimised ensuring the efficient use of the NHS resources [17-19]. Without a means to identify whether a patient is taking their medication and the reason for non-adherence (unintentional due to forgetfulness or intentional/deliberate) their benefit from those medications will be limited [19].

More than 15 million people in England (30\% of the population) have one or more long-term medical conditions [20]. Many of these also experience $\mathrm{MIH}$, which represents one of the top three causes of death in the UK $[15,19]$. People living with diabetes and COPD are three times more likely to have depression than the general population [19]. Up to $33 \%$ of women and more than $20 \%$ of men with all types of arthritis also may have co-morbid depression [20]. It is estimated that long-term conditions account for around $70 \%$ of total UK spending on health, of which $£ 8-£ 13$ billion are for MIH alone [19]. The role of the pharmacist in providing early support to people with long-term conditions and early identification of MIH could be beneficial in the management of their disease and compliance with their medication $[15,19]$.

Early identification of MIH is crucial to the provision of effective support for people with long-term conditions and may contribute to reducing the excess costs associated with complications [19]. Nine out of ten people with MIH are treated in primary care and $90 \%$ of adults with severe mental health problems are also supported by community services [15]. The RPS recommends the skills and expertise of pharmacists should be utilised in the multidisciplinary management of patients with MIH, especially in the community [16]. Most deprived areas in the UK usually have access to community pharmacies, which are easily accessed with longer opening hours than many medical practices and no need for pre-booked appointments. Many people with long-term conditions who are also living with MIH live in deprived areas with access to fewer resources of all kinds, as manifested as clear health inequalities [19]. The King's Fund recommended that Clinical commissioning groups (CCGs) should prioritise integrating mental and physical health care more closely as a key part of their improvement strategies [19].

It is estimated that there are $>900,000$ adults (aged 18 and older) with intellectual disabilities in England (2013 census data), with 350,000 people registered as blind or partially sighted [20]. People living with sensory impairments have a greater lifetime risk of developing MIH [20]. According to WHO, MIH and substance use disorders are the leading cause of disability worldwide causing about $23 \%$ of all years lost due to disability [20]. This accounts for $23 \%$ of the total 'burden of disease' in the United Kingdom [19]. They also represent the leading cause of disability in children and young people globally [21]. Public Health England (PHE) estimates that, in 2015, up to 35,000 adults with a learning disability were prescribed an antipsychotic medication, an antidepressant or both, without appropriate clinical justification [19]. People with learning disabilities may have difficulty identifying important symptoms and gaining initial access to appropriate care. They may also find it difficult to correctly take medications that have long and complex instructions and which use inaccessible language [22]. Since 31st July 2016, pharmacists are required to comply with the Accessible Information Standard, which requires providers of NHS and adult social care to identify, record, flag, share and meet the information and communication support needs of people with a disability or sensory loss [23]. The UK Action on Hearing Loss estimates that more than 9 million people in England have some form of hearing loss, projected to be 15.6 million by 2035 [23]. The impact of MIH in the workplace affects both the individual and the productivity of the entire organization [24]. According to the UK DoH and the Confederation of British Industry, $15-30 \%$ of workers will experience some form of MIH during their working lives. In the UK, 80 million days are lost annually due to MIH, costing employers $£ 1-2$ billion each year. Those in the poorest $20 \%$ of the UK population are twice as likely to develop MIH compared to those on an average income [24].

\section{Aim}

The aim of this local audit was to compare the local population to the national and global population, to inform the development and 
provision of local pharmacy MIH screening services to support patients diagnosed with long-term conditions.

\section{MATERIALS AND METHODS}

This project was designed as an audit of anonymised local data, to inform the development of services offered by community pharmacies to improve adherence to therapy amongst patients diagnosed with long-term conditions in the Black Country, UK. The audit forms part of a larger study, granted ethical approval by the Health Research Authority in 2018. A total of 652 patients' pharmacy records were reviewed between March and April 2020. There were no patient identifiers included in the reviewed data, which was analysed using Microsoft ${ }^{\circledR}$ Excel $^{\mathrm{TM}}$.

\section{RESULTS}

Table 1 shows the local population ethnicity by age group, where the majority of patients are white (94\%). This is representative of the local population census data of $90 \%$. The second-largest ethnic group was
Asian of $6 \%$ compared to $5.6 \%$ of the population and $1.8 \%$ Black people compared to $1.7 \%$ of the population of the borough. The majority of the records (90\%) were for patients between the age of 31 and 90 (31-50 y of age at 29\%, 51-70 y of age at 38\%, 71-90 y of age at $22 \%$ ). Compared to the local population of $64 \%$ from the same age group; $(22.5 \%, 27.5 \%$ and $14 \%$, respectively). This means that the results of this analysis might not be applicable to the entire local population outside the 31-90 y of age range.

The number of patients in each medical disorder category was counted (table 2). The highest number of medical conditions identified in a white person's records was 12 in a $53 \mathrm{y}$ old, one of which was MIH this was followed by an Asian $60 \mathrm{y}$ old of 10 conditions of which one was a mental illness and 6 conditions in a black $65 \mathrm{y}$ old person and no mental illness. This further highlights the unique characteristics of health determinants and service utilisation for different ethnicity, where in the UK black and Asian are grouped under black and minority ethnic (BAME) group.

Table 1: Ethnicity by age group

\begin{tabular}{llll}
\hline Age in years & Asian & Black & White \\
\hline $18-30$ & 4 & 1 & 63 \\
$31-50$ & 18 & 2 & 170 \\
$51-70$ & 8 & 4 & 233 \\
$71-100$ & 2 & 1 & 146 \\
\hline
\end{tabular}

Table 2: Number of patients diagnosed with long-term conditions by body system

\begin{tabular}{|c|c|c|c|c|c|}
\hline Age in years & 18-30 & 31-50 & 51-70 & 71-100 & Total \\
\hline Cardiovascular disorders & 5 & 69 & 141 & 117 & 332 \\
\hline Pain and central nervous system disorders & 17 & 80 & 100 & 63 & 260 \\
\hline Mental disorders & 28 & 91 & 86 & 28 & 233 \\
\hline Gastrointestinal disorders & 5 & 41 & 84 & 70 & 200 \\
\hline Respiratory disorders & 16 & 54 & 67 & 41 & 178 \\
\hline Endocrine disorders & 5 & 24 & 40 & 37 & 160 \\
\hline Vitamins and minerals deficiencies & 4 & 21 & 39 & 43 & 107 \\
\hline Infection & 9 & 23 & 34 & 22 & 88 \\
\hline Genitourinary disorders & 6 & 18 & 24 & 35 & 83 \\
\hline Musculoskeletal disorders & 2 & 18 & 33 & 23 & 76 \\
\hline Eye/ear/nose/throat & 3 & 11 & 20 & 27 & 61 \\
\hline Skin & 3 & 12 & 21 & 18 & 54 \\
\hline Others & 0 & 3 & 7 & 2 & 12 \\
\hline Oncology & 0 & 2 & 4 & 4 & 10 \\
\hline
\end{tabular}

The mean number of medications per age group was then calculated. The highest number of medications used was in the 31-50 y group, followed by the $51-70 \mathrm{y}, 71-100 \mathrm{y}$ and lastly was the $18-30 \mathrm{y}$ of age groups (table 3).

Table 3: Mean number (and range) of medications per person by age group

\begin{tabular}{lll}
\hline Age in years & Mean (range) of total number of medications & Mean (Range) of number of medications for mental disorders \\
\hline $18-30 \mathrm{n}=68$ & $6.5(0-12)$ & $1.5(0-3)$ \\
$31-50 \mathrm{n}=190$ & $14.5(1-28)$ & $2.5(0-4)$ \\
$51-70 \mathrm{n}=245$ & $16.5(1-32)$ & $2(0-3)$ \\
$71-100 \mathrm{n}=149$ & $8(1-17)$ & $2(0-3)$ \\
\hline
\end{tabular}

Table 4 shows the mean number of medications per ethnicity. There was no significant difference between the groups. However, in the black group, there was no use of MIH medications, which may indicate under utilisations of services, while in the Asian group there was higher utilization than both white and black population. This requires further investigation. The highest number of medications used by one person was 32 , where one patient had 31 for long-term conditions and one for MIH (Asian-60 y of age), followed by a white patient (45 y of age) who had 28 medications for long-term conditions and three medications for MIH.

Table 4: Mean number (and range) of medications per person per ethnicity

\begin{tabular}{lll}
\hline Ethnicity & Mean of total number of medications & Mean of medications for mental disorders \\
\hline Asian $\mathrm{n}=32$ & $4.2(1-32)$ & $1(0-1)$ \\
Black $\mathrm{n}=8$ & $3.5(1-10)$ & $0(0)$ \\
White $\mathrm{n}=612$ & $4.7(1-28)$ & $0.4(0-3)$ \\
\hline
\end{tabular}

Medications from different categories were further analysed. Common side effects which may impact the long-term conditions patients MIH or cognitive function were documented (table 5). From the top 50 medications, $64 \%(n=32)$ have mood-affecting side effects including anxiety, depression, altered mood, sleep disorders, depersonalisation, abnormal dreams, depression, mania, psychotic disorders, hallucinations and suicidal ideation. There were $36 \%$ $(n=18)$ medications with anticholinergic side effects that affect cognition (impaired concentration, memory loss and confusion). Additionally, there were $18 \%(n=9)$ of medications can cause hyponatraemia which may lead to cognitive issues (amongst many other issues) when severe and overlooked. 
Table 5: Top 5 medications by system

\begin{tabular}{|c|c|c|c|}
\hline Disorders & $\begin{array}{l}\text { Patients } \\
\text { number }\end{array}$ & Mood side effects & Hyponatremia and anticholinergic burden \\
\hline \multicolumn{4}{|l|}{ Mental disorders } \\
\hline Citalopram & 49 & Anxiety, sleep disorders, depersonalisation & Hyponatremia, impaired concentration, confusion $(\mathrm{ACB}=1)$ \\
\hline Sertraline & 49 & Anxiety, sleep disorders, depersonalisation & Hyponatremia, impaired concentration, confusion $(\mathrm{ACB}=2)$ \\
\hline Mirtazapine & 36 & Anxiety, sleep disorders & Hyponatremia, impaired concentration, confusion $(\mathrm{ACB}=1)$ \\
\hline Fluoxetine & 32 & Anxiety, sleep disorders & Hyponatremia, impaired concentration, confusion $(\mathrm{ACB}=1)$ \\
\hline Diazepam & 17 & $\begin{array}{l}\text { Anxiety, depression, altered mood, sleep } \\
\text { disorders, suicidal ideation }\end{array}$ & Incoordination, confusion $(\mathrm{ACB}=1)$ \\
\hline \multicolumn{4}{|l|}{ Endocrine-diabetes } \\
\hline Metformin & 59 & & \\
\hline Gliclazide & 22 & Depression, anxiety, headache, nervousness & \\
\hline Insulin combined & 20 & & \\
\hline Alogliptin & 8 & & \\
\hline Empagliflozin & 7 & & \\
\hline \multicolumn{4}{|l|}{ Gastro-Intestinal } \\
\hline Lansoprazole & 101 & Depression, sleep disorders & Hyponatremia, confusion $(\mathrm{ACB}=1)$ \\
\hline Omeprazole & 53 & Depression, sleep disorders & Hyponatremia, confusion $(\mathrm{ACB}=1)$ \\
\hline Laxative combined & 28 & & Electrolyte abnormalities \\
\hline Mebeverine & 7 & & \\
\hline Ranitidine & 6 & Depression, hallucination & Confusion $(\mathrm{ACB}=1)$ \\
\hline \multicolumn{4}{|l|}{ Cardiovascular } \\
\hline Atorvastatin & 126 & Depression, sleep disorders & Memory loss, confusion $(\mathrm{ACB}=1)$ \\
\hline Bisoprolol & 84 & Depression, hallucination, sleep disorders & Confusion $(\mathrm{ACB}=1)$ \\
\hline Ramipril & 76 & Sleep disorders & Electrolyte abnormalities \\
\hline Aspirin & 68 & & \\
\hline Amlodipine & 64 & Depression & \\
\hline \multicolumn{4}{|l|}{ Respiratory } \\
\hline Salbutamol & 118 & & \\
\hline $\begin{array}{l}\text { Beclomethasone } \\
\text { dipropionate }\end{array}$ & 38 & Anxiety & \\
\hline $\begin{array}{l}\text { Beclomethasone/ } \\
\text { formoterol }\end{array}$ & 31 & Anxiety & \\
\hline Budesonide/formoterol & 25 & Anxiety, sleep disorders & \\
\hline Fluticasone/formoterol & 19 & Anxiety, sleep disorders & \\
\hline \multicolumn{4}{|l|}{ Central Nervous } \\
\hline Codeine/Paracetamol & 99 & Euphoric mood, hallucination & Confusion $(\mathrm{ACB}=1)$ \\
\hline Paracetamol & 46 & & \\
\hline Gabapentin & 35 & Depression, sleep disorders & \\
\hline Pregabalin & 21 & Altered mood, anxiety, hallucination & Impaired concentration, memory loss, confusion $(\mathrm{ACB}=1)$ \\
\hline Zopiclone & 19 & $\begin{array}{l}\text { Anxiety, depressed mood, depression, } \\
\text { hallucination, sleep disorders }\end{array}$ & $\begin{array}{l}\text { Cognitive disorder, impaired concentration, delusions } \\
(\mathrm{ACB}=1)\end{array}$ \\
\hline \multicolumn{4}{|r|}{$\begin{array}{llll} & \end{array}$} \\
\hline Doxycycline & 24 & & \\
\hline Clarithromycin & 10 & $\begin{array}{l}\text { Depersonalisation, abnormal dreams, } \\
\text { depression, mania, psychotic disorders }\end{array}$ & \\
\hline Amoxicillin & 8 & & \\
\hline Flucloxacillin & 6 & & \\
\hline $\begin{array}{l}\text { Phenoxy-methyl } \\
\text { penicillin }\end{array}$ & 4 & & \\
\hline \multicolumn{4}{|l|}{ Other Endocrine } \\
\hline Levothyroxine & 56 & Anxiety, sleeping disorders & \\
\hline Prednisolone & 32 & $\begin{array}{l}\text { Anxiety, sleeping disorders, behaviour } \\
\text { abnormalities, altered mood }\end{array}$ & Electrolyte imbalance, cognitive impairment $(\mathrm{ACB}=1)$ \\
\hline Carbimazole & 5 & & \\
\hline Estradiol & 3 & Anxiety, depression & \\
\hline Conjugated Oestrogens & 2 & Anxiety, depression, altered mood & \\
\hline \multicolumn{4}{|l|}{ Genito-Urinary } \\
\hline Doxazosin & 25 & Anxiety, depression, sleep disorders & \\
\hline Tamsulosin & 11 & & \\
\hline Finasteride & 9 & & \\
\hline Solifenacin & 9 & Hallucination & Confusion $(\mathrm{ACB}=3)$ \\
\hline Desogestrel & 8 & Depressed mood, altered mood & \\
\hline \multicolumn{4}{|l|}{ Others } \\
\hline Quinine & 20 & & Confusion $(\mathrm{ACB}=1)$ \\
\hline Naproxen & 16 & Depression, hallucination, sleep disorders & Impaired concentration, confusion $(\mathrm{ACB}=1)$ \\
\hline Allopurinol & 14 & Depression & \\
\hline Diclofenac & 11 & Anxiety, depression, sleep disorders & Memory loss, confusion $(\mathrm{ACB}=1)$ \\
\hline Alendronic acid & 8 & & \\
\hline
\end{tabular}

*According to FOX et al. (2011) [25] anticholinergic burden (ACB) defined as: Drugs with possible anticholinergic effects were defined as those with serum anticholinergic activity or in vitro affinity to muscarinic receptors but with no known clinically relevant negative cognitive effects (ACB score =1). Drugs with established and clinically relevant cognitive anticholinergic effects were considered to be definite anticholinergics (ACB score 2-3). *Anticholinergic burden CNS symptoms are: Delirium, agitation, disorientation, and visual hallucinations. Ataxia, choreoathetosis, myoclonus and seizures may also occur without peripheral symptoms. 


\section{DISCUSSION}

\section{Cardiovascular diseases}

In the records reviewed, cardiovascular diseases (CVD) were present in $51 \%(n=332)$ of all patients. Approximately 17.9 million people died from CVDs in 2016 and it is known to be the largest cause of death worldwide [26]. It is widely acknowledged that experiencing a major cardiac event can increase the risk of developing mental health problems such as depression [27]. Corell et al. stated that in patients with severe MIH such as schizophrenia, bipolar affective disorder and major depressive disorder, the risk of CVD increased by 2-3X compared to the general population [28, 29]. A meta-analysis by Barth et al. analysed 29 studies involving HF patients and concluded that patients diagnosed with depression and myocardial infarction had a 2 to 2.6 times greater risk of death than those without a depression diagnosis [30]. A large observational study of $1,937,360$ adults with no history of CVD found that depression was associated with an increased risk of HF development even in healthy patients. The researchers also claimed that there was no difference in the risk of suffering from 12 different CVDs contrasting with the claims of other researchers [31].

Studies suggest the medication patients take can be the reason for the increased susceptibility to physical illness such as CVD [28]. For example; weight gain is a common side effect of antipsychotic drugs affecting up to $72 \%$ of patients during the initiation and maintenance phase of treatment. $<$ sup $>32,33</$ sup $>$ It has been established that depression is common in patients who experienced a stroke and can present up to 2-3 y post the acute event [34]. This post-stroke depression may be of biological origin due to neuronal damage causing a reduction in neurotransmitter release in the catecholamine pathway $[35,36]$. The incidence of Dementia post stoke was investigated by Ivan et al., who studied 212 subjects who were dementia-free in January 1982, and had their first stroke after this date. They found that after a $10 \mathrm{y}$ follow up $19.3 \%$ of these participants developed dementia compared to $11 \%$ of controls. They postulated this may be due to atherosclerotic disease.

\section{Diabetes}

In the records reviewed, diabetes constituted $25 \%(n=160)$ of all patients. WHO estimates that diabetes will affect more than 350 million persons worldwide by 2030 [37] and that the number of people who have diabetes would double in the year 2000 [37]. In $2014,8.5 \%$ of adults aged 18 y and older had diabetes. In 2016, it was the documented cause of 1.6 million deaths and it is estimated 642 million people worldwide will have diabetes by 2040 [38]. The rate of depression among people living with diabetes through their lifetime is $2 \mathrm{X}$ greater than that of the general population [37, 39]. Diabetes distress is defined as the psychological distress specific to living with diabetes $[40,41]$ It is estimated that this may affect as many as one in four people living with type 1 diabetes mellitus and one in five people with type 2 [42]. Factors such as feeling guilt when self-management does not control the disease, concern about the possibility of serious complications or being overwhelmed with the complexity of their diabetes treatment regimen and life-long commitment are the main causes of diabetes-related distress [40, 41]. The result of diabetes-related depression can be long-term and result in lack of self-care and non-adherence to medication $[40,42]$. Anxiety affects about $30 \%$ of the adult population [43]. People living with diabetes report increased anxiety and anxiety disorder but the overall prevalence in diabetes is similar to the general populace [42]. Around $14 \%$ of people with diabetes have generalized anxiety, which results in poor glycaemic control [37]. Additionally, people with diabetes have a greater tendency to be involved in behaviours associated with eating disorders [44, 45] People with Type 1 diabetes sometimes engage in 'Diabulimia', aiming for weight loss $[42,46]$. This can have a dangerous effect on health and life. Depression itself has a high co-morbidity with eating disorders [47]. Individuals with type 2 diabetes are sometimes associated with night eating syndrome (NES). This is when an individual eats more than $25 \%$ of their daily caloric intake after the evening meal, waking up at night to eat, on average, at least 3 times a week [47]. This can result into weight gain, poor control of their diabetes and complications resulting from this. NICE UK states that dementia affects 850,000 people within the UK today, projected to reach over 1 million by 2025 [7]. Cukierman et al. found a considerable decline in cognitive function in patients with diabetes compared to patients without diabetes (1.6X) [48]. These findings were also supported by Biessels et al. who stated that diabetes is a condition associated with hypertension and atherosclerotic disease that contribute to cognitive decline through cerebrovascular disease [49].

\section{Parkinson disease}

In the records reviewed, there were $1 \%(n=4)$ of all patients diagnosed with Parkinson's disease (PD). PD affects $2-3 \%$ of the population $65 \mathrm{y}$ old and over [50]. Mood disturbance, anxiety, depression are the most common in PD [51]. Studies focussing on depression as a symptom in people diagnosed with $\mathrm{PD}$, found that $40-50 \%$ of all PD patients are affected by MIH [52]. Treatment of depression in PD patients has frequently been poor at around $26 \%$, often due to the lack of diagnosis because of overlapping symptoms [52]. Findings suggest the use of traditional first-line agents such as SSRIs are the favoured option in terms of efficacy and tolerability [53]. Patients with PD are 2-6X more likely to develop dementia than healthy controls. PD dementia can affect $50 \%$ of patients within whom mild cognitive impairment becomes gradually worse with time [51]. This correlation was noted by Aarsland et al., who found that more than $75 \%$ of his study cohort of PD patients developed dementia during their 8 y study [54].

\section{Rheumatoid arthritis}

In the records reviewed, there were $2 \%(n=8)$ of all patients diagnosed with Rheumatoid arthritis (RA). RA is a common chronic inflammatory disease presenting between the ages of 20 and $40 \mathrm{y}$ of age $[55,56]$. RA is associated with pain, an increase in comorbid risks, musculoskeletal deficits, decline in physical function, socialization and quality of life $[56,57]$. The prevalence of RA varies between $0.3 \%$ and $1 \%$; and is more common in women and in developed countries.[56] WHO states that within $10 \mathrm{y}$ of onset, at least $50 \%$ of patients in developed countries are unable to undertake full-time work [56]. RA is associated with an increased prevalence of both depression and anxiety [58, 59]. Jacob et al., found that in their study sample of RA patients, $23.7 \%$ of men and $36 \%$ of women developed depression [55]. A meta-analysis of 72 studies concluded that depression and RA comorbidity is associated with poorer RA outcomes [60]. Lwin et al. specify that depression is higher in RA than the general population by $2 \mathrm{X}$ [61]. One study highlighted that in their sample, $11 \%$ (13 out of 123) experienced suicidal ideation [62]. Patients with RA of more than four years duration are more likely to report suicidal ideation $(12 \%)$ vs those with less than two years duration (7\%) [63]. Finally, Vallerand et al. reported that RA and depression comorbidity affect patients' coping strategies, medication compliance and the effectiveness of treatment; increasing the risk of disease flares and decreasing the rates of remission [64]. The effect of disease-modifying antirheumatic drugs (DMARDS) on the development of dementia in patients diagnosed with RA was identified [65]. They found that patients who used methotrexate, hydroxychloroquine and leflunomide had a $1.63 \mathrm{X}$ higher risk of dementia than patients who did not take these drugs.

\section{Respiratory disease}

In the records reviewed, respiratory conditions constituted $27 \%$ $(n=178)$ of all patients. Psychological disorders, in particular depression and anxiety, have been shown to have a close link to asthma and COPD [66, 67]. Distress and powerful emotions can increase the risks of a person diagnosed with asthma developing anxiety [68]. COPD has been associated with increased exhaustion, which decreases exercise tolerance. This can hinder a patient from carrying out basic daily activities increasing the risk of developing depression and anxiety [69]. Yohannes found that anxiety and depression was more frequent in COPD patients who smoked, compared to those who did not [70]. Atlantis et al. (2013) concluded that depression and anxiety could worsen COPD worse in patients and precipitate exacerbations [71]. COPD could also increase the risk of developing depression. Janssen et al. found results that support the connection between dyspnea and depression. They established depression was more common in those patients who had severe 
shortness of breath [72] Liao et al. stated that patients with COPD have a greater risk of developing dementia compared to non-COPD patients with the risk increasing with increasing age [73].

\section{CONCLUSION}

The Pharmaceutical Services Negotiating Committee states that approximately 1.6 million people visit a pharmacy in England every day. These encounters range from seeking general advice to discussing complex long-term health conditions and other comorbidities. In addition; community pharmacists are open for extended hours; often including weekends in contrast to other health care premises. The utilization of community pharmacists and their staff can help in addressing the rising challenge of the longterm health conditions and MIH comorbidities.

It is was proven during the COVID-19 that pharmacists are in good position as easy accessible health care facilities to support patients especially when the other NHS facilities are overwhelmed or closed. It is recommended that the New Medicines Service include mental health disorders patients prescribed pharmacological therapy and to allow the pharmacists appropriate access to medical records to deliver safe, integrated and effective patient care. Additionally, community pharmacies are in a position to offer large-scale screening programs such as self-completed anxiety, depression and cognitive function screening surveys and refer to general practitioners for further investigations.

\section{FUNDING}

This research received no external funding.

\section{AUTHORS CONTRIBUTIONS}

All the authors have contributed equally.

\section{CONFLICTS OF INTERESTS}

The authors declare no conflict of interest.

\section{REFERENCES}

1. The role of pharmacy in mental health and wellbeing. Available from: https://www.rpharms.com/recognition/all-our-campaigns/ policy-a-z/pharmacy-in-mental-health-and-wellbeing. [Last accessed on 22 Jan 2021].

2. Singleton N, Bumpstead R, O'Brien M, Lee A, Meltzer H. Psychiatric morbidity among adults living in private households 2000. Null 2003;15:65-73.

3. NHS Health Scotland. Good Mental Health for All (Guidance); 2016. p. 1-32.

4. World Health Organisation. Mental health action plan 20132020; 2013. p. 1-45.

5. Mental Health Foundation. Surviving or thriving the state of the UK's mental health; 2020. p. 1-26.

6. The Mental Health Policy Group. A manifesto for better health; 2015. p. 1-16.

7. Dementia: assessment, management and support for people living with dementia and their carers. Available from: https://www.nice.org.uk/guidance/ng97. [Last accessed on 21 Jan 2021].

8. NHS England. NHS five-year forward view. COVID-19 UK (COGUK) Consortium; 2014.

9. NHS England. Next steps on the NHS five year forward view; 2017. p. 1-75.

10. Mental health "game-changer" care leads to 75 percent reduction in hospital admissions. Available from: Mental Health Foundation. Surviving or thriving the state of the UK's mental health. Available from: https://www.wired-gov.net/wg/ news.nsf/articles/Mental+health+gamechanger+care+leads+to +75+per+cent+reduction+in+hospital+admissions+150520180 91500?open. [Last accessed on 22 Jan 2021].

11. McMillan SS, Kelly F, Hattingh HL, Fowler JL, Mihala G, Wheeler AJ. The impact of a person-centered community pharmacy mental health medication support service on consumer outcomes. J Ment Health 2018;27:164-73.

12. Kane JM, Kishimoto T, Correll CU. Non-adherence to medication in patients with psychotic disorders: epidemiology, contributing factors and management strategies. World Psychiatry 2013;12:216-26.

13. Royal Pharmaceutical Society of, G B. No health without mental health: How can pharmacy support people with mental health problems? 2018. p. 1-22.

14. MHFA England. Adult mental health first aid manual. London: Mental Health First Aid England; 2016. p. 278.

15. The mental health task force. The Mental Health Five Year Forward View; 2016. p. 1-82.

16. Royal Pharmaceutical Society of, G B. Utilising pharmacists to improve the care for people with mental health problems; 2018. p. 1-10.

17. Elliott RA, Boyd MJ, Tanajewski L, Barber N, Gkountouras G, Avery AJ, et al. 'New medicine service': supporting adherence in people starting a new medication for a long-term condition: 26week follow-up of a pragmatic randomised controlled trial. BMJ Qual Saf 2020;29:286-95.

18. Barber N, Parsons J, Clifford S, Darracott R, Horne R. Patients' problems with new medication for chronic conditions. Qual Saf Health Care 2004;13:172-5.

19. Naylor C, Parsonage M, McDaid D. Long-term conditions and mental health the cost of co-morbidities. Centre for Mental Health; 2012. p. 1-32.

20. World Health Organisation. 10 Facts about Mental health; 2019. p. 10.

21. Erskine HE, Moffitt TE, Copeland WE, Costello EJ, Ferrari AJ, Patton G, et al. A heavy burden on young minds: the global burden of mental and substance use disorders in children and youth. Psychol Med 2015;45:1551-63.

22. Prout T. Community pharmacies are uniquely positioned to help people with disabilities; 2016. p. 1.

23. Accessible Information Standard. Available from: https://www.e-lfh.org.uk/accessible-information-standard/. [Last accessed on 22 Jan 2021]

24. Mental Health Foundation. Fundamental facts about mental health; 2016. p. 1-112.

25. Fox C, Richardson K, Maidment ID, Savva GM, Matthews FE, Smithard D, et al. Anticholinergic medication use and cognitive impairment in the older population: the medical research council cognitive function and ageing study. J Am Geriatr Soc 2011;59:1477-83.

26. World Health Organisation. About cardiovascular diseases. Available from: https://www.who.int/ cardiovascular_ diseases/about_cvd/en/. [Last accessed 22 Jan 2021].

27. Celano CM, Huffman JC. Depression and cardiac disease: a review. Cardiol Rev 2011;19:130-42.

28. Correll CU, Detraux J, De Lepeleire J, De Hert M. Effects of antipsychotics, antidepressants and mood stabilizers on risk for physical diseases in people with schizophrenia, depression and bipolar disorder. World Psychiatry 2015;14:119-36.

29. De Hert M, Detraux J, Vancampfort D. The intriguing relationship between coronary heart disease and mental disorders. Dialogues Clin Neurosci 2018;20:31-40.

30. Barth J, Schumacher M, Herrmann Lingen C. Depression as a risk factor for mortality in patients with coronary heart disease: a meta-analysis. Psychosom Med 2004;66:802-13.

31. Daskalopoulou M, George J, Walters K, Osborn DP, Batty GD, Stogiannis D, et al. Depression as a risk factor for the initial presentation of twelve cardiac, cerebrovascular, and peripheral arterial diseases: data linkage study of 1.9 million women and men. PLoS One 2016;11:e0153838.

32. DE Hert M, Correll CU, Bobes J, Cetkovich Bakmas M, Cohen D, Asai I, et al. Physical illness in patients with severe mental disorders. I. Prevalence, impact of medications and disparities in health care. World Psychiatry 2011;10:52-77.

33. McElroy SL, Kotwal R, Malhotra S, Nelson EB, Keck PE, Nemeroff $\mathrm{CB}$. Are mood disorders and obesity related? A review for the mental health professional. J Clin Psychiatry 2004;65:634-51.

34. Anu B, Palomaki Heikki, Matti L, Lonnqvist Jouko, Markku K. Poststroke Depression. Stroke 2003;34:138-43.

35. Parikh RM, Lipsey JR, Robinson RG, Price TR. Two-year longitudinal study of post-stroke mood disorders: dynamic changes in correlates of depression at one and two years. Stroke 1987;18:579-84. 
36. Dieguez S, Staub F, Bruggimann L, Bogousslavsky J. Is poststroke depression a vascular depression? J Neurol Sci 2004;226:53-8.

37. Lin EH, Von Korff M, Alonso J, Angermeyer MC, Anthony J, Bromet E, et al. Mental disorders among persons with diabetes-results from the world mental health surveys. J Psychosom Res 2008;65:571-80.

38. International Diabetes Federation. Diabetes Atlas Ninth Edition 2019; 2019. p. 120.

39. Ducat L, Philipson LH, Anderson BJ. The mental health comorbidities of diabetes. JAMA 2014;312:691-2.

40. Perrin NE, Davies MJ, Robertson N, Snoek FJ, Khunti K. The prevalence of diabetes-specific emotional distress in people with type 2 diabetes: a systematic review and meta-analysis. Diabet Med 2017;34:1508-20.

41. Fisher L, Hessler D, Polonsky W, Strycker L, Masharani U, Peters A. Diabetes distress in adults with type 1 diabetes: prevalence, incidence and change over time. J Diabetes Complications 2016;30:1123-8.

42. Beba H, Jukes D. Diabetes: mental health considerations in adults (CPD-Review). Pharm J 2020;1:1-7.

43. Smith KJ, Deschênes SS, Schmitz N. Investigating the longitudinal association between diabetes and anxiety: a systematic review and meta-analysis. Diabet Med 2018;35:677-93.

44. Gagnon C, Aime A, Belanger C, Markowitz JT. Comorbid diabetes and eating disorders in adult patients: assessment and considerations for treatment. Diabetes Educ 2012;38:537-42.

45. Dipnall JF, Pasco JA, Meyer D, Berk M, Williams LJ, Dodd S, et al. The association between dietary patterns, diabetes and depression. J Affect Disord 2015;174:215-24.

46. Hoffman B. Diabulimia-cultural determinants of eating disorders. Trakia J Sci 2019;2:187-95.

47. All parliamentary party group for diabetes. Diabetes and Mental Health; 2018. p. 1-21.

48. Cukierman T, Gerstein HC, Williamson JD. Cognitive decline and dementia in diabetes--systematic overview of prospective observational studies. Diabetologia 2005;48:2460-9.

49. Biessels GJ, Staekenborg S, Brunner E, Brayne C, Scheltens P. Risk of dementia in diabetes mellitus: a systematic review. Lancet Neurol 2006;5:64-74.

50. Williams Gray C, Worth PF. Parkinson's disease. Medicine 2016;44:542-6.

51. Marinus J, Zhu K, Marras C, Aarsland D, van Hilten JJ. Risk factors for non-motor symptoms in Parkinson's disease. Lancet Neurol 2018;17:559-68.

52. Hemmerle AM, Herman JP, Seroogy KB. Stress, depression and Parkinson's disease. Exp Neurol 2012;233:79-86.

53. Marsh L. Depression and Parkinson's disease: current knowledge. Curr Neurol Neurosci Reports 2013;13:409.

54. Aarsland D, Andersen K, Larsen JP, Lolk A, Kragh Sørensen P. Prevalence and characteristics of dementia in Parkinson disease: an 8y prospective study. Arch Neurol 2003;60:387-92.

55. Jacob EL, Gatto NM, Thompson A, Bordelon Y, Ritz B. Occurrence of depression and anxiety prior to Parkinson's disease. Parkinsonism Relat Disord 2010;16:576-81.
56. Chronic rheumatic conditions. Available from: https://www.who.int/chp/topics/rheumatic/en/. [Last accessed on 22 Jan 2021]

57. Smolen JS, Aletaha D, McInnes IB. Rheumatoid arthritis. Lancet 2016;388:2023-38.

58. Machin A, Hider S, Dale N, Chew-Graham C. Improving recognition of anxiety and depression in rheumatoid arthritis: a qualitative study in a community clinic. Br J Gen Pract 2017;67:e531-7.

59. VanDyke MM, Parker JC, Smarr KL, Hewett JE, Johnson GE, Slaughter JR, et al. Anxiety in rheumatoid arthritis. Arthritis Rheum 2004;51:408-12.

60. Matcham F, Rayner L, Steer S, Hotopf M. The prevalence of depression in rheumatoid arthritis: a systematic review and meta-analysis. Rheumatology (Oxford) 2013;52:2136-48.

61. Lwin MN, Serhal L, Holroyd C, Edwards CJ. Rheumatoid arthritis: the impact of mental health on disease: a narrative review. Rheumatol Ther 2020;7:457-71.

62. Del Giacco SR, Cappai A, Gambula L, Cabras S, Perra S, Manconi $\mathrm{PE}$, et al. The asthma-anxiety connection. Respir Med 2016;120:44-53.

63. Treharne GJ, Lyons AC, Kitas GD. Suicidal ideation in patients with rheumatoid arthritis. Research may help identify patients at high risk. Br Med J 2000;321:1290.

64. Vallerand IA, Patten SB, Barnabe C. Depression and the risk of rheumatoid arthritis. Curr Opin Rheumatol 2019;31:279-84.

65. Chou MH, Wang JY, Lin CL, Chung WS. DMARD use is associated with a higher risk of dementia in patients with rheumatoid arthritis: a propensity score-matched case-control study. Toxicol Appl Pharmacol 2017;334:217-22.

66. Harrison BD. Psychosocial aspects of asthma in adults. Thorax 1998;53:519-25.

67. Yohannes AM, Baldwin RC, Connolly MJ. Mood disorders in elderly patients with chronic obstructive pulmonary disease. Rev Clin Gerontol 2000;10:193-202.

68. Krommydas GC, Gourgoulianis KI, Angelopoulos NV, Kotrotsiou E, Raftopoulos V, Molyvdas PA. Depression and pulmonary function in outpatients with asthma. Respir Med 2004;98:220-4

69. Pumar MI, Gray CR, Walsh JR, Yang IA, Rolls TA, Ward DL. Anxiety and depression-important psychological comorbidities of COPD. J Thorac Dis 2014;6:1615-31.

70. Yohannes AM, Alexopoulos GS. Depression and anxiety in patients with COPD. J Eur Res Soc 2014;23:345-9.

71. Atlantis E, Fahey P, Cochrane B, Smith S. Bidirectional associations between clinically relevant depression or anxiety and COPD: a systematic review and meta-analysis. Chest 2013;144:766-77.

72. Janssen DJ, Spruit MA, Leue C, Gijsen C, Hameleers H, Schols JM, et al. Symptoms of anxiety and depression in COPD patients entering pulmonary rehabilitation. Chron Respir Dis 2010;7:147-57.

73. Liao KM, Ho CH, Ko SC, Li CY. Increased risk of dementia in patients with chronic obstructive pulmonary disease. Medicine (Baltimore) 2015;94:e930. 